\title{
Stratification of Single-Vessel Coronary Stenosis by Ischemic Threshold at the Onset of Wall Motion Abnormality During Continuous Monitoring of Left Ventricular Function by Semisupine Exercise Echocardiography
}

Jérôme Garot, MD, Etienne P. Hoffer, MD, Jean-Luc Monin, MD, Anne-Marie Duval, MD, Luc A. Piérard, MD, and Pascal Guéret, MD, Créteil, France, and Liège, Belgium

\begin{abstract}
We studied the relation between the ischemic threshold at the onset of wall motion abnormality on exercise echocardiography (EE) and the severity of coronary stenosis in patients with 1-vessel coronary artery disease (CAD). We screened 216 consecutive patients who underwent coronary angiography and EE for suspected CAD. Ninety-five ( 74 men; age, $56 \pm$ 12 years) satisfied the study criteria, that is, the presence of 1-vessel disease or no evidence of CAD on angiography and a normal baseline echocardiogram. Eighty-seven patients had 1-vessel CAD on angiography, and exercise-induced wall motion abnormality occurred in $73(77 \%)$. Optimal cutoff
\end{abstract}

\footnotetext{
$\mathbf{T}_{\mathrm{h}}$ he assessment of the ischemic threshold during exercise stress testing has been limited mainly to the examination of electrocardiographic changes, which is a relatively insensitive marker of myocardial ischemia. ${ }^{1-}$ 3 Consequently, the relation between the ischemic threshold assessed by electrocardiographic changes during exercise and coronary arteriography has been poorer than expected. ${ }^{3}$ Exercise echocardiography (EE) is an accepted tool for the assessment of the functional significance of coronary obstructions among patients with coronary artery disease (CAD) ${ }^{4-8}$ In previous reports, the classification of CAD has been mostly semiquantitative, assessed by visual analysis, or

From the Departments of Cardiology of the Henri Mondor University Hospital, Créteil, France, and the Sart-Tilman Hospital, Lièger, Belgium, (E.P.F., L.A.P.).

Reprint requests: Jérôme Garot, MD, Department of Medicine, Cardiology Division, Blalock 569, Johns Hopkins Medical Institutions, $600 \mathrm{~N}$ Wolfe St, Baltimore MD, 21287-6568 (E-mail: jgarot@mail.jhmi.edu).

Copyright (c) 2001 by the American Society of Echocardiography. $0894-7317 / 2001 / \$ 35.00+0 \quad 27 / 1 / 111936$

doi: $10.1067 / \mathrm{mje} .2001 .111936$
}

values of percent diameter stenosis and minimal lumen diameter for predicting a positive EE were $61 \%$ (sensitivity and specificity of $76 \%$ ) and $1.12 \mathrm{~mm}$ (sensitivity and specificity of $74 \%$ ). Among patients with positive EE, heart rate-blood pressure product at ischemic threshold was correlated with quantitative coronary stenosis $(r=-0.72, P<.001)$. The ischemic threshold from continuous monitoring of left ventricular function during semisupine $E E$ is correlated with the severity of coronary stenosis among patients with 1-vessel disease and a normal resting echocardiogram. ( $\mathrm{J}$ Am Soc Echocardiogr 2001;14:798-805.)

based on predetermined cutoff values of angiographic parameters. ${ }^{4,5,7-10} \mathrm{~A}$ few studies that used quantitative analysis of coronary stenosis have demonstrated the diagnostic accuracy of EE for the detection of significant CAD in selected patients with single-vessel disease and normal echocardiograms at rest. ${ }^{1,2}$ They have established that the severity of a coronary stenosis assessed by quantitative coronary angiography can predict an ischemic response on $\mathrm{EE}$ and that the functional significance of a coronary narrowing is better correlated to exercise-induced wall motion abnormality (WMA) on echocardiography than other usual markers of exercise-induced myocardial ischemia. As opposed to stress scintigraphy, stress echocardiography allows for the assessment of the ischemic threshold by determining the level of myocardial oxygen demand at which ischemia develops. However, the analysis of the ischemic threshold on stress echocardiography has been performed only during pharmacologic stress. ${ }^{11,12}$ Continuous monitoring of left ventricular (LV) function by EE offers the unique possibility of assessing a more physiologic ischemic threshold by 
providing real-time analysis of the functional consequences of exercise-induced myocardial ischemia. Whether this measurement correlates with angiographic indexes of the severity of coronary artery stenosis remains unknown.

We evaluated the diagnostic accuracy of the occurrence of stress-induced wall motion abnormality on $\mathrm{EE}$ for the detection of significant CAD in a large population of patients with single-vessel disease or without coronary stenosis. Among patients with an ischemic response on $\mathrm{EE}$, we investigated the relation between quantitative coronary stenosis and the ischemic threshold identified by continuous monitoring of regional $\mathrm{LV}$ function.

\section{METHODS}

\section{Screened Population}

We screened 216 consecutive patients who had no history of myocardial infarction and who underwent EE and coronary angiography in our institutions. Reasons to perform echocardiography were the evaluation of chest pain in 185 patients, whereas 17 were enrolled in follow-up studies after percutaneous transluminal coronary angioplasty; the other 14 had an equivocal treadmill exercise stress test. Inclusion criteria were (a) no history of previous infarction, (b) normal echocardiograms at rest, (c) withdrawal of all antianginal medications at least 48 hours before echocardiography, (d) coronary artery stenosis limited to 1 major vessel or no evidence of CAD at angiography performed within 1 week of echocardiography. Patients with unstable angina, left bundle branch block, LV hypertrophy, or heart transplantation were not included. Study protocol was approved by the local ethics committee, and informed consent was obtained from patients.

\section{Exercise Echocardiography Protocol}

Semisupine bicycle EE was performed with stepwise increments of work load ( $30 \mathrm{~W}$ every 3 minutes). A single-lead electrocardiogram was continuously monitored. Heart rate, blood pressure, and a 12-lead electrocardiogram were recorded at baseline, automatically every 3 minutes throughout the study, at peak stress, and during recovery. The decision to terminate the study was made by real-time assessment of regional wall thickening during exercise. An ischemic response on $\mathrm{EE}$ was called when exerciseinduced WMA $\geq 1$ grade occurred in at least 1 myocardial segment. Among patients with a positive echocardiogram, the ischemic threshold, as assessed by the heart rate-systolic blood pressure product, was determined on-line by consensus between 2 experts in the interpretation of stress echocardiography. Echocardiographers were blinded to patient status and angiographic data. The occurrence of stress-induced horizontal or downsloping ST-segment depression $>1 \mathrm{~mm} 80 \mathrm{~ms}$ after the $\mathrm{J}$ point on electrocardiography indicated myocardial ischemia. Reasons for terminating the study were (a) heart rate equal to or greater than maximal age-predicted heart rate, (b) development of WMA, (C) exercise-induced chest pain with electrocardiographic evidence of myocardial ischemia, (d) decrease of systolic blood pressure $>30 \mathrm{~mm} \mathrm{Hg}$, and (e) repetitive ventricular ectopic beats $(\geq 3)$ and ventricular tachycardia.

\section{Image Acquisition and Analysis}

Two-dimensional echocardiograms were recorded with Acuson 128/XP or Sequoia (Mountain View, Calif) and Vingmed System Five (Trondheim, Norway), equipped with a 2.5- to 3.5-MHz phased-array transducer. Images of parasternal long-axis, short-axis, and apical 4- and 2-chamber views were continuously monitored throughout the study and digitized on-line at baseline, peak exercise, and during recovery, with the patient lying in the same left lateral semisupine position. When myocardial ischemia was detected, a whole set of images was immediately acquired and stored during exercise ( 4 views typically acquired in $<1$ minute), and the patient was allowed to recover. When Acuson 128/XP was used, digitization was performed with an automated acquisition system (Image Vue DCR 1.41, Nova Microsonics, Mahwah, NJ) with R-wave triggering and allowing storage of 10 frames during $560 \mathrm{~ms}$ after the $\mathrm{R}$ wave. Images were suitable for analysis when a good detection of endocardial boundary was achieved, requiring in some patients the use of second harmonic imaging. To evaluate the accuracy of the on-line assessment of regional WMA, images were continuously recorded on S-VHS videotape throughout the study and stored for off-line analysis of regional LV function with a 16-segment, 4-grade scale model. ${ }^{13}$ Images were analyzed off-line by an independent investigator unaware of the on-line assessment of LV function.

\section{Quantitative Arteriographic Data}

All patients underwent coronary angiography with a conventional Judkins technique performed within 1 week of EE. Percent diameter stenosis and minimal lumen diameter were measured by an independent observer blinded to echocardiographic data, through the use of an interactive validated software (CASS). ${ }^{14}$ Calibration of measurements to absolute values was achieved by using the catheter tip as a scaling device. All measurements were performed from end-diastolic frames with optimal vessel opacification.

\section{Statistical Analysis}

Data are expressed as mean \pm SD. We used an unpaired Student $t$ test to compare data among patients with and 


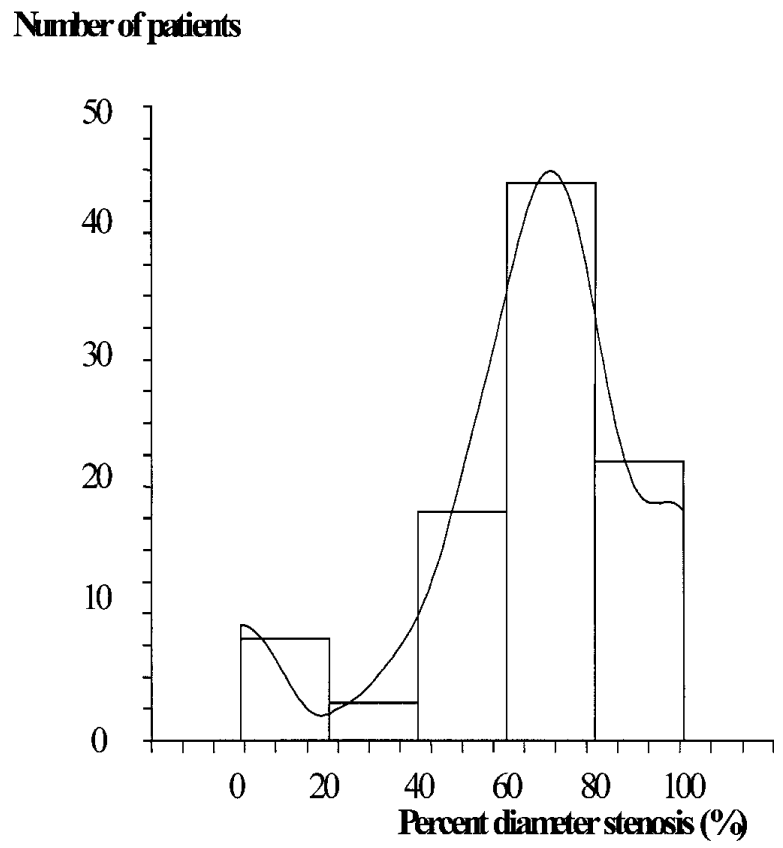

Figure 1 Distribution of severity of coronary stenosis as assessed by percent diameter stenosis (\%) in study population.

without a positive response on EE. Receiver-operator characteristic curve analysis was used to assess the sensitivity and specificity of angiographic parameters for the prediction of an ischemic response on EE. The optimal cutoff was chosen as the point of interception between sensitivity and specificity of each parameter. Linear regression analysis was used to determine the correlation between the ischemic threshold and quantitative coronary stenosis. On the basis of the presence or the absence of an ischemic response on $\mathrm{EE}$, a $\kappa$ reliability test was used to assess the correlation between the on-line and off-line analyses of LV function at peak stress. All tests were 2 -tailed, and a value of $P<.05$ was considered statistically significant.

\section{RESULTS}

\section{Study Population}

The study population consisted of 95 patients $(74$ men; mean age, $56 \pm 12$ years) with no history of myocardial infarction, normal echocardiograms at rest, and no antianginal medications at the time of echocardiography. Of the 216 screened patients, 121 could not be included in the study because of multivessel disease and/or abnormal echocardiogram at rest in 99, ongoing antianginal medications in 11 , poor quality of echocardiographic images in 3 , left bundle branch block in 5, and LV hypertrophy in 3 .
Table 1 Baseline characteristics of the study population

\begin{tabular}{lc}
\hline Patients (n) & 95 \\
Age (y) & $56 \pm 12$ \\
Sex [n (\%)] & $74(78)$ \\
$\quad$ Male & $21(22)$ \\
Female & $65 \pm 26$ \\
Stenosis (\%) & $0.99 \pm 0.80$ \\
MLD (mm) & $68 \pm 10$ \\
Baseline heart rate (beats/min) & $130 \pm 18$ \\
Baseline systolic blood pressure (mm Hg) & $77(81)$ \\
Ischemic response on EE [n (\%)] & $31(33)$ \\
ST depression [n (\%)] & $20(21)$ \\
Angina [n (\%)] & \\
Coronary artery [n (\%)] & $40(46)$ \\
LAD & $32(37)$ \\
RCA & $13(15)$ \\
LCX & $2(2)$ \\
LMCA &
\end{tabular}

$M L D$, Minimum lumen diameter; $E E$, exercise electrocardiography; $L A D$, left anterior descending; $R C A$, right coronary artery; $L C X$, left circumflex; $L M C A$, left main coronary artery.

Baseline characteristics of the study population are shown in Table 1 . The mean percent diameter stenosis assessed by quantitative angiography performed 3 \pm 2 days apart from echocardiography was $65.0 \% \pm$ $26.4 \%$ (range, $0 \%$ to $100 \%$ ) and the mean minimal lumen diameter was $0.99 \pm 0.80 \mathrm{~mm}$ (range, 0.00 to $3.20 \mathrm{~mm}$ ). There were no clinical events between stress echocardiography and catheterization. The distribution of percent diameter stenosis is shown in Figure 1. Eighty-seven patients had evidence of single-vessel coronary artery stenosis (percent diameter stenosis from $20 \%$ to $100 \%$ ). The left anterior coronary artery was involved in 40 (46\%), the right coronary artery in 32 (37\%), the left circumflex artery in $13(15 \%)$, and the left main in $2(2 \%)$.

\section{Echocardiographic Data}

Seventy-seven (81\%) patients had a positive response on EE. Of these, 73 had their test terminated because of the occurrence of WMA during continuous monitoring of $\mathrm{LV}$ function. In the 4 remaining patients, the procedure was stopped because of significant changes and/or chest pain. Among patients with a positive response on EE, significant ST-segment depression on electrocardiography occurred in 31 (40\%) and chest pain in 20 (26\%). The mean number of ischemic myocardial segments was $2.2 \pm 1.2$ (range, 1 to 5). A stress-induced drop of systolic blood pressure $>30 \mathrm{~mm} \mathrm{Hg}$ relative to baseline occurred in 5 patients. All had WMA on echocardiography involving at least 4 myocardial segments; 3 had a severe stenosis of the proximal left anterior descending artery and 2 had a significant stenosis of the left main 
Table 2 Baseline characteristics and hemodynamics in patients with and without ischemic response on exercise echocardiography

\begin{tabular}{lccc}
\hline & $\begin{array}{c}\text { Negative } \\
\text { response } \\
(\mathbf{n = 1 8 )}\end{array}$ & $\begin{array}{c}\text { Ischemic } \\
\text { response } \\
(\mathbf{n = 7 7 )}\end{array}$ & $\begin{array}{c}\boldsymbol{P} \\
\text { value }\end{array}$ \\
\hline Age (y) & $57 \pm 10$ & $56 \pm 12$ & $\mathrm{NS}$ \\
Men [n (\%)] & $13(72)$ & $61(79)$ & NS \\
Diabetes [n (\%)] & $3(17)$ & $11(14)$ & NS \\
Hypertension [n (\%)] & $6(33)$ & $22(29)$ & NS \\
Hypercholesterolemia [n (\%)] & $5(28)$ & $21(37)$ & NS \\
Smokers [n (\%)] & $9(50)$ & $41(53)$ & NS \\
Baseline heart rate (beats/min) & $66 \pm 9$ & $68 \pm 10$ & NS \\
Baseline SBP (mm Hg) & $130 \pm 15$ & $130 \pm 19$ & NS \\
\hline
\end{tabular}

NS, Not significant; $S B P$, systolic blood pressure.

coronary artery. In 3 patients, the study was stopped because of repetitive $(\geq 3)$ ventricular ectopic beats; all had a negative response on EE. We did not observe sustained ventricular tachycardia in any of the study patients. Baseline characteristics and hemodynamics were similar among patients with and without ischemic response (Table 2). Percent diameter stenosis and minimal lumen diameter were significantly different in patients with positive versus negative $\mathrm{EE}(74 \% \pm 17 \%$ versus $29 \% \pm 30 \%$ and $0.74 \pm$ $0.59 \mathrm{~mm}$ versus $2.06 \pm 1.00 \mathrm{~mm}$, respectively, $P<$ .01 ). Among patients with a negative response, the mean work load and heart rate-systolic blood pressure product at peak stress were higher than in patients with positive EE $(171 \pm 35 \mathrm{~W}$ versus $124 \pm$ $43 \mathrm{~W}$ and $27,005 \pm 3689$ vs $18,201 \pm 4815$, respectively, $P<.0001)$. In these patients, the mean maximal heart rate reached during the study was $87 \% \pm$ $7 \%$ (range, $75 \%$ to $100 \%$ ) of the maximal age-predicted heart rate.

On-line versus off-line assessment of regional $\mathbf{~ L V}$ function. Of the 73 patients with on-line positivity on $\mathrm{EE}, 4$ had a negative response when assessed offline. Similarly, of the 22 patients with a negative test as assessed on-line, 3 had a positive response when reviewed off-line. Thus there was an agreement between the two observers in $93 \%$ of patients. For the overall population, agreement between on-line and off-line assessment of regional $\mathrm{LV}$ function was good between 2 independent observers, with a $\mathrm{K}$ coefficient of 0.80 . To evaluate the accuracy of the on-line assessment of the ischemic threshold, we measured the mean time to the occurrence of WMA during the on-line and off-line analyses in 20 randomly selected patients with a positive response. The mean difference between both series of measurements was small $(597 \pm 139$ seconds on-line versus $583 \pm 139$ seconds off-line, not significant), and
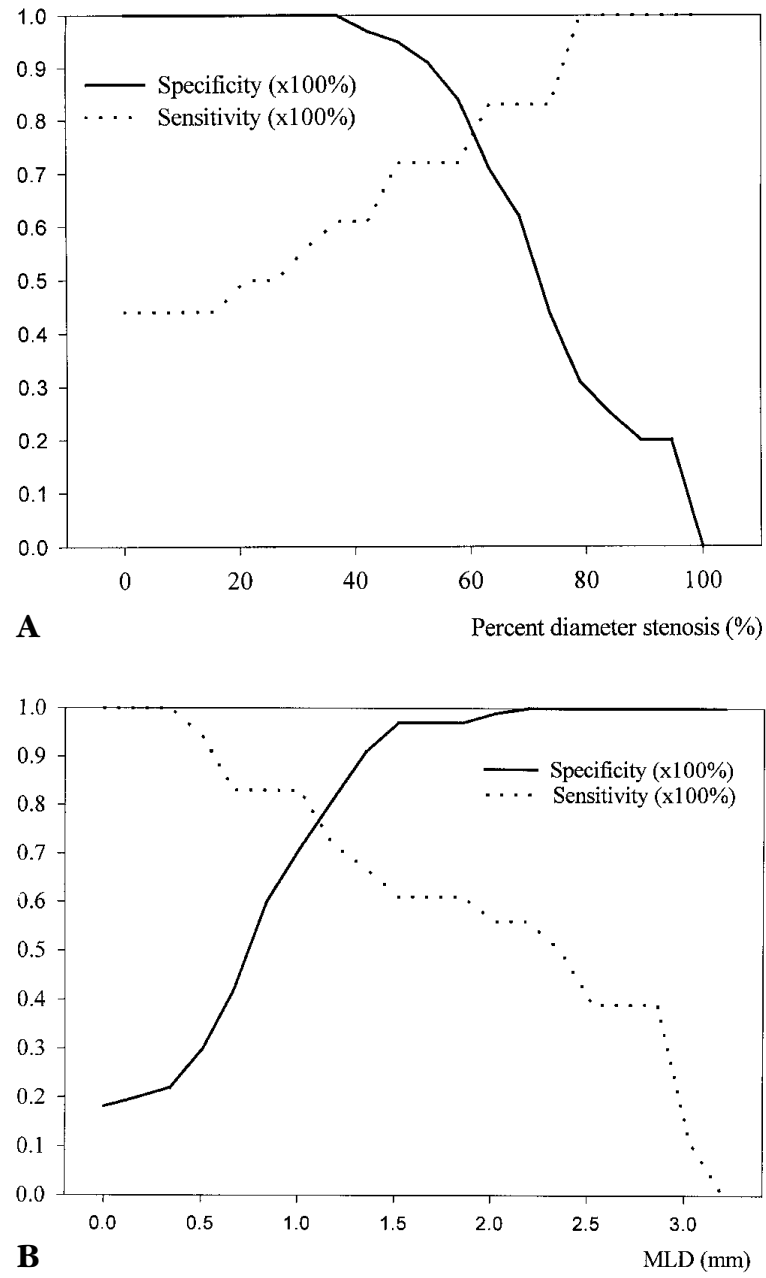

Figure 2 Percent correct classification of presence (sensitivity) or absence (specificity) of exercise-induced wall motion abnormality on echocardiography as function of whole spectrum of percent diameter stenosis (A) and minimal lumen diameter (B).

the two serial measurements were correlated $(y=$ $0.95 x+23.2, r=0.97, P<.001)$.

\section{Relation of Echocardiographic Data to Quantitative Coronary Stenosis}

The sensitivity and specificity of the individual values of percent diameter stenosis and minimal lumen diameter for the prediction of the occurrence of WMA on EE are shown in Figure 2. The optimal cutoff value of percent diameter stenosis for predicting a positive response was $61 \%$, yielding a sensitivity and specificity of $76 \%$. Similarly, the best cutoff value of the minimal lumen diameter was $1.12 \mathrm{~mm}$ (sensitivity and specificity of $74 \%$ ). Figure 3 displays the receiver-operator characteristic curves comparing the diagnostic accuracy of percent diameter stenosis and minimal lumen diameter for the prediction of 


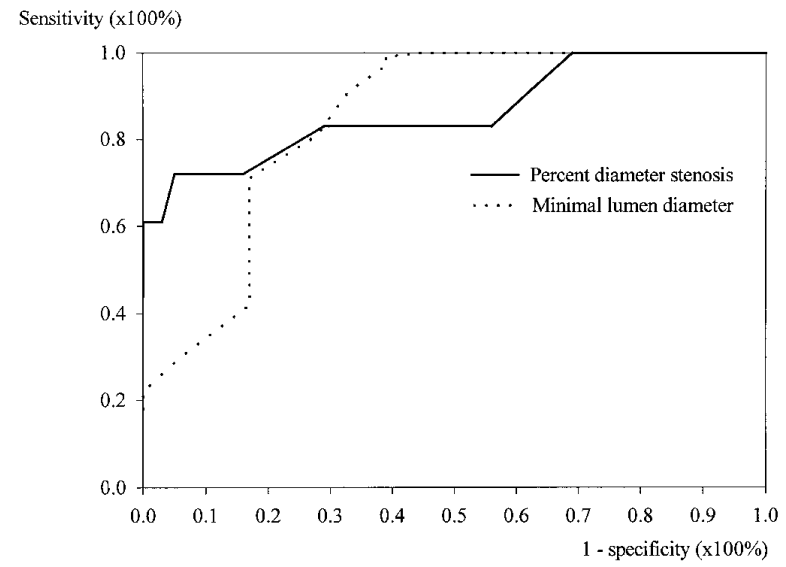

Figure 3 Receiver-operator characteristic curves for diagnostic accuracy of percent diameter stenosis and minimal lumen diameter for occurrence of exercise-induced wall motion abnormality on echocardiography. Because areas under curves were not statistically different (8670 versus 8480 , respectively), predictive values of both angiographic variables were similar.

transient WMA on EE. Areas under the curves were not significantly different (8670 and 8480 , respectively). The heart rate-blood pressure product at the ischemic threshold in patients with a positive response was correlated with quantitative coronary stenosis expressed as percent diameter $(r=-0.72, P$ $<.0001)$ and minimal lumen diameter $(r=0.65, P<$ .0001) (Figure 4). In these patients, the relation between the heart rate at ischemic threshold and quantitative coronary stenosis was poorer $(r=$ $-0.52, P<.01$, and $r=0.46, P<.01$, respectively). However, in patients with a positive response, a heart rate at ischemic threshold $\leq 112$ beats/min was able to predict the presence of a coronary stenosis $\geq 70 \%$ with a sensitivity and specificity of $81 \%$ (Figure 5).

Among patients with positivity on EE, the mean number of ischemic myocardial segments was $2.2 \pm$ 1.2 (range, 1 to 5). There was no significant correlation between the number of segments developing WMA during exercise and percent diameter stenosis on angiogram $(r=0.16)$. Moreover, the duration of exercise in patients with positive EE (mean time, 611 \pm 172 seconds) was poorly related to the severity of stenosis $(r=0.34, P<.05)$.

\section{DISCUSSION}

The main finding of this study is that the ischemic threshold, as assessed by the occurrence of transient WMA on continuous monitoring of LV function during semisupine EE, is closely related to the severity of
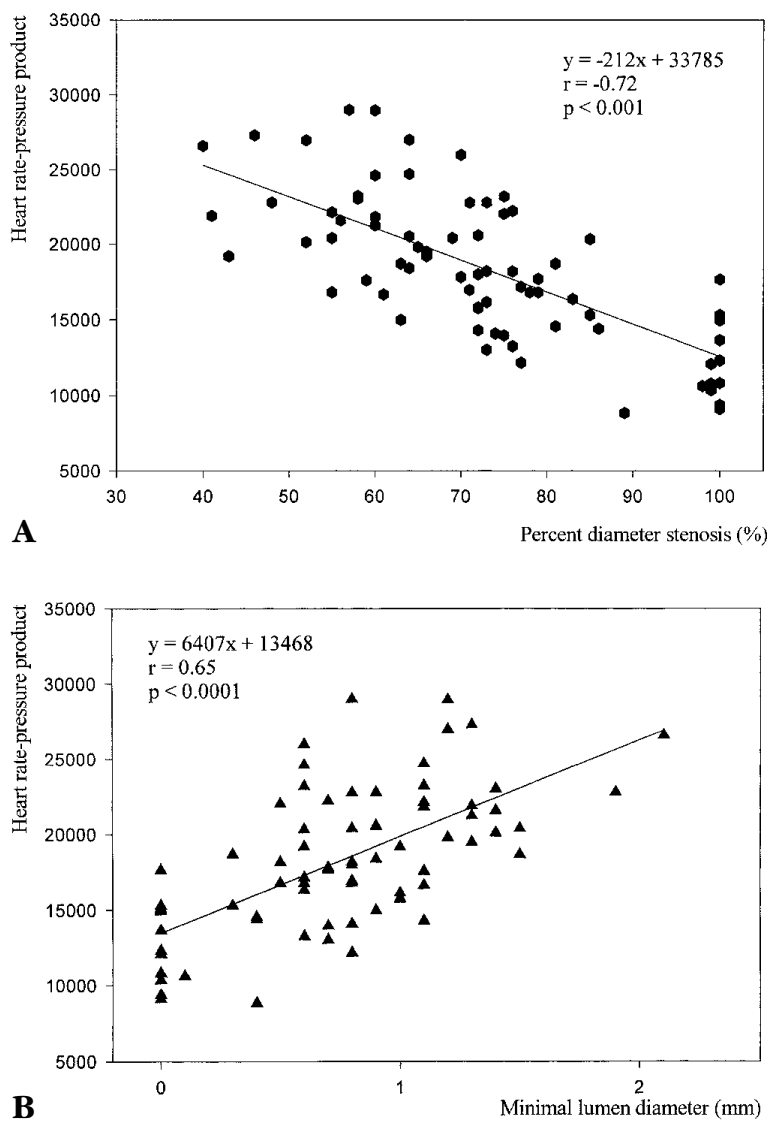

Figure 4 Correlation between ischemic threshold as assessed by exercise echocardiography and severity of coronary obstruction expressed as percent diameter stenosis $(\mathbf{A}, r=-0.72, P<.0001)$ and minimal lumen diameter $(\mathbf{B}$, $r=0.65, P<.0001)$ in patients with positive exercise echocardiography.

quantitative coronary stenosis in patients with single-vessel CAD and a normal resting echocardiogram. The intensity of cardiac work load at which ischemia occurs is of critical importance for the interpretation of exercise stress testing. A high work threshold of ischemia-induced electrocardiographic changes usually reflects moderate coronary obstruction, whereas the development of ischemia at a low level of exertion reflects severe coronary obstructive disease and indicates a poor prognosis. ${ }^{15}$ Despite the good agreement between exercise tests and clinical follow-up, the correlation between exercise electrocardiography and coronary angiography has been poor. 3,16 Indeed, ST-segment depression as assessed by electrocardiography represents a relatively insensitive marker of myocardial ischemia. ${ }^{1,2}$ Several studies have shown a poor relation between the heart rate at the point of induction of WMA and at the onset of significant ST-segment depression during stress 
echocardiography. ${ }^{11,17-19}$ Those findings are concordant with our study, suggesting that the ischemic threshold extracted from continuous monitoring of LV function during EE could represent a reliable tool for the evaluation of the severity of coronary stenosis. ${ }^{20,21}$ Our data also confirm the diagnostic accuracy of EE for the detection of patients with single-vessel CAD. ${ }^{1,2}$

\section{Relation Between Electrocardiographically Determined Ischemic Threshold and Severity of Coronary Stenosis}

A few studies have suggested that there is a relation between the ischemic threshold assessed during pharmacologic stress echocardiography and the severity of coronary artery stenosis among patients with single-vessel disease. The ischemic threshold measured during dobutamine echocardiography correlates with the number of stenosed vessels and the LV ejection fraction response to exercise. ${ }^{11}$ The degree of dobutamine-induced asynergy on peak stress echocardiography has been shown to correlate significantly with the severity of coronary artery stenosis and slightly better with myocardial fractional flow reserve. ${ }^{22}$ In patients with single-vessel disease, normal echocardiograms at rest, and positive dipyridamole echocardiography, the regional coronary flow reserve assessed by positron emission tomography correlates well with dipyridamole time $(r=$ 0.87). ${ }^{12}$ Our study is the first one that has specifically addressed the relation between the ischemic threshold determined from EE and the severity of coronary stenosis. Our data indicate that a stratification of the severity of coronary stenosis can be obtained among patients with single-vessel CAD, based on the assessment of the ischemic threshold during EE. These findings suggest that there might be a relation between the ischemic threshold assessed by stress echocardiography and the coronary flow reserve in these patients. ${ }^{23}$ In support of this, experimental studies have demonstrated that the degree of coronary obstruction represents one of the main factors that limit subendocardial perfusion during stress-induced myocardial ischemia and correlates to the degree of myocardial dysfunction. ${ }^{24-26}$

\section{Clinical Implications}

The additional value of monitoring the ischemic threshold in the study population permits a stratification of the severity of coronary stenosis. This was not possible when assessing the ischemic threshold on treadmill stress tests because the onset of electrocardiographic abnormalities or chest pain is known to be unrelated to the ischemic threshold itself. The

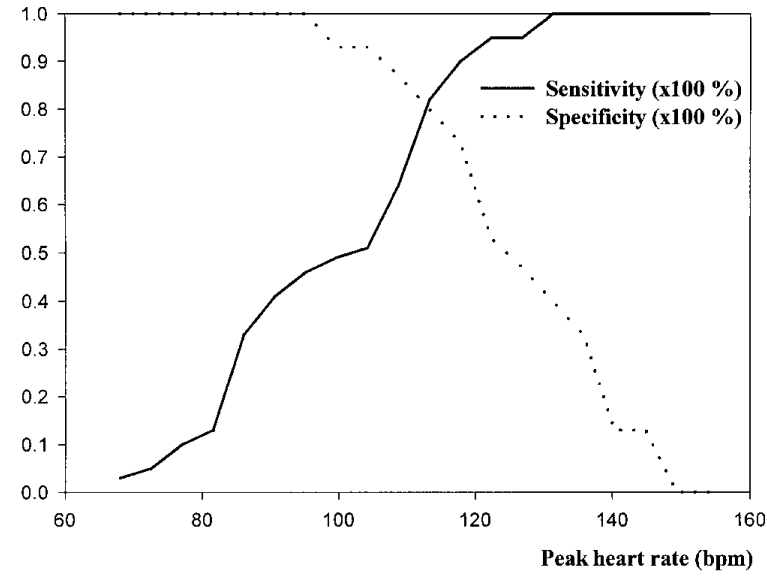

Figure 5 Receiver-operator characteristic curves showing that maximal heart rate at ischemic threshold $\leq 112$ beats/min in patients with positive response on echocardiography was able to detect coronary stenosis $\geq 70 \%$ with sensitivity and specificity of $81 \%$.

relation between the ischemic threshold on exercise echocardiography and angiographic severity of coronary stenosis, although highly significant, is somewhat scattered when considering the entire population of the study. However, our results might be helpful for noninvasively determining the physiologic severity of a coronary stenosis in the same patients followed over time, for example, for the detection of restenosis after a percutaneous revascularization procedure. Decision-making among patients with chest pain and intermediate coronary stenosis remains difficult. It has recently been reported that in patients referred for percutaneous angioplasty of an intermediate coronary stenosis, deferral of the intervention on the basis of a relatively preserved coronary flow reserve is safe and associated with a lower clinical event rate. ${ }^{27-29}$ Although more work is needed, EE appears to be a promising tool for noninvasive determination of the physiologic relevance of coronary lumen narrowing at the bedside and may have potential for subsequent stratification of the need of coronary revascularization among patients with 1vessel CAD.

\section{Advantages and Limitations}

In this study, we chose to evaluate myocardial ischemia by the continuous recording method of semisupine 2dimensional EE. Exercise myocardial scintigraphy plays an important role in defining the hemodynamic significance of coronary artery lesions. ${ }^{30,31}$ However, EE has been shown to have at least a similar diagnostic accuracy as perfusion scintigraphy among patients studied by the two methods. ${ }^{32}$ Scintigraphy 
evaluates myocardial perfusion heterogeneity at peak exercise and therefore does not offer the possibility to assess the ischemic threshold. Echocardiograms recorded immediately after treadmill exercise induces a greater ischemic burden than dobutamineatropine echocardiography, suggesting that $\mathrm{EE}$ should be preferred in the clinical setting over dobutamine echocardiography among patients who are capable of exercising. ${ }^{33}$ Advantages of peak exercise imaging over postexercise echocardiography have been discussed elsewhere. ${ }^{34} \mathrm{~A}$ false-negative response on EE among patients with significant coronary artery stenosis correlates well with the performance of a submaximal exercise ( $<85 \%$ of the maximal agepredicted heart rate), single-vessel disease, and moderate stenoses from $50 \%$ to $70 \%{ }^{7}$ In the current report, the mean maximal heart rate achieved among patients with a negative response on EE was $87 \%$ of the maximal predicted heart rate.

Our data support the concept that exercise duration is poorly related to the severity of coronary obstruction. 35 We chose to assess the heart rate-systolic blood pressure product at the ischemic threshold, which is an externally derived indicator of myocardial oxygen needs, because it has been shown to contribute to increased test accuracy. 36

The ischemic threshold was assessed on-line during the procedure, and a consensus was achieved by two experts in the analysis of regional LV function during stress echocardiography. Although this method is subjective, it is still the conventional method for making the decision to terminate the test during routine interpretation of diagnostic stress echocardiography. Moreover, we demonstrated the reliability and reproducibility of the on-line identification of the ischemic threshold during EE.

Although the current study shows a relation between the ischemic threshold assessed during EE and quantitative coronary stenosis, dispersion of the individual data was observed. It is well established that physiologic effects of the majority of coronary obstructions cannot be accurately determined by conventional angiographic approaches. The measurement of the percent diameter stenosis from coronary angiography is not closely related to the reactive hyperemic response. ${ }^{23,37}$ In this regard, the coronary blood flow reserve might have been better correlated to the ischemic threshold in our study population. ${ }^{22}$ However, the measurement of the coronary narrowing as percent diameter stenosis or minimal lumen diameter by a computerized method offers the advantage to be easily accessible and widely available.
Thus the ischemic threshold assessed by the occurrence of transient exercise-induced WMA during continuous monitoring of $\mathrm{LV}$ function on semisupine EE allows for stratification of the severity of coronary stenosis among patients with single-vessel disease and a normal echocardiogram at rest. EE may provide important information on the functional significance and severity of single-vessel coronary stenosis and might be a valuable tool for stratifying the need for coronary revascularization in these patients.

\section{REFERENCES}

1. Salustri A, Arnese M, Boersma E, Cornel JH, Baptista J, Elhendy A, et al. Correlation of coronary stenosis by quantitative coronary arteriography with exercise echocardiography. Am J Cardiol 1995;75:287-90.

2. Arnese M, Salustri A, Fioretti PM, Cornel JH, Boersma E, Reijs AEM, et al. Quantitative angiographic measurements of isolated left anterior descending coronary stenosis: correlation with exercise echocardiography and technetium-99m 2methoxy isobutyl isonitrile single-photon emission computed tomography. J Am Coll Cardiol 1995;25:1486-91.

3. McNeer JF, Margolis JR, Lee KL, Kisslo JA, Peter RH, Kong $\mathrm{Y}$, et al. The role of the exercise test in the evaluation of patients for ischemic heart disease. Circulation 1978;57:6470.

4. Ryan T, Vasey CG, Presti CF, O'Donnell JA, Feigenbaum H, Armstrong WF. Exercise echocardiography: detection of coronary artery disease in patients with normal left ventricular wall motion at rest. J Am Coll Cardiol 1988;11:993-9.

5. Crouse LJ, Harbrecht JJ, Vacek JL, Rosamond TL, Kramer $\mathrm{PH}$. Exercise echocardiography as a screening test for coronary artery disease and correlation with arteriography. Am J Cardiol 1991;67:1212-8.

6. Salustri A, Pozzoli MMA, Hermans W, Ilmer B, Cornel JH, Reijs AEM, et al. Relationship between exercise echocardiography and perfusion single photon emission computed scintigraphy in patients with single-vessel coronary artery disease. Am Heart J 1992;124:75-84.

7. Marwick T, Nemec J, Pashkow F, Steward WJ, Salcedo E. Accuracy and limitations of exercise echocardiography in a routine clinical setting. J Am Coll Cardiol 1992;19:74-81.

8. Sawada SG, Ryan T, Fineberg NS, Armstrong WF, Judson WE, McHenry PL, et al. Exercise echocardiography for detection of coronary artery disease in women. J Am Coll Cardiol 1989;14:1440-7

9. Sheikh KH, Bengtson JR, Helmy S, Juarez C, Burgess R, Bashore TM, et al. Relation of quantitative coronary lesion measurements to the development of exercise-induced ischemia assessed by exercise echocardiography. J Am Coll Cardiol 1990;15:1043-51.

10. Agati L, Arata L, Luongo R, Iacoboni C, Renzi M, Vizza $\mathrm{CD}$, et al. Assessment of severity of coronary narrowings by quantitative exercise echocardiography and comparison with quantitative arteriography. Am J Cardiol 1991;67:1201-7.

11. Panza JA, Curiel RV, Laurienzo JM, Quyyumi AA, Dilsizian V. Relation between ischemic threshold measured during dobutamine stress echocardiography and known indices of 
poor prognosis in patients with coronary artery disease. Circulation 1995;92:2095-101.

12. Picano E, Parodi O, Lattanzi F, Sambuceti G, Andrade MJ, Marzullo P, et al. Assessment of anatomic and physiological severity of single-vessel coronary artery lesions by dipyridamole echocardiography: comparison with positron emission tomography and quantitative arteriography. Circulation 1994;89:753-61.

13. Monin JL, Garot J, Scherrer Crosbie M, Rosso J, DuvalMoulin AM, Dupouy P, et al. Prediction of functional recovery of viable myocardium after delayed revascularization in postinfarction patients: accuracy of dobutamine stress echocardiography and influence of long-term vessel patency. J Am Coll Cardiol 1999;34:1012-9.

14. Reiber JHC, Serruys PW, Slager CJ. Quantitative coronary and left ventricular cineangiography: methodology and clinical application. Dordrecht, The Netherlands: Martinus Nijhoff, 1986:162-89.

15. Ellestad MH, Wan MKC. Predictive implications of stress testing: follow-up of 2200 subjects after maximum treadmill stress testing. Circulation 1975;51:363-9.

16. Ferro G, Durilio C, Spinelli L, Liucci GA, Mazza F, Indolfi C. Relation between diastolic perfusion time and coronary artery stenosis during stress-induced myocardial ischemia. Circulation 1995;92:342-7.

17. Cohen JL, Greene TO, Ottenweller J, Binenbaum SZ, Wilchfort SD, Kim CS. Dobutamine digital echocardiography for detecting coronary artery disease. Am J Cardiol 1991;67:1311-8.

18. Segar DS, Brown SE, Sawada SG, Ryan T, Feigenbaum H. Dobutamine stress echocardiography: correlation with coronary lesion severity as determined by quantitative angiography. J Am Coll Cardiol 1992;19:1197-202.

19. Cohen JL, Ottenweller JE, George AK, Duvvury S. Comparison of dobutamine and exercise echocardiography for detecting coronary artery disease. Am J Cardiol 1993;72: 1226-31

20. Mitsuhashi T, Shiina A, Kuroda T, Yamasawa M, Fujita T, Suzuki $\mathrm{O}$, et al. Predicting the severity of coronary lesions by the continuous recording method of exercise two-dimensional echocardiography. J Am Soc Echocardiogr 1995;8:703-9.

21. Brener SJ, Pashkow FJ, Harvey SA, Marwick TH, Thomas JD, Lauer MS. Chronotropic response to exercise predicts angiographic severity in patients with suspected or stable coronary artery disease. Am J Cardiol 1995;76:1228-32.

22. Bartunek J, Marwick TH, Rodrigues AC, Vincent M, Van Schuerbeeck E, Sys SU, et al. Dobutamine-induced wall motion abnormalities: correlations with myocardial fractional flow reserve and quantitative coronary angiography. J Am Coll Cardiol 1996;27:1429-36.

23. Uren NG, Melin JA, DeBruyne B, Wijns W, Baudhuin T, Camici PG. Relation between myocardial blood flow and the severity of coronary-artery stenosis. N Engl J Med 1994;330: 1782-8.

24. Nabel EG, Selwyn AP, Ganz P. Paradoxical narrowing of ath- erosclerotic coronary arteries induced by increases in heart rate. Circulation 1990;81:850-9.

25. Epstein SE, Talbot TL. Dynamic coronary tone in precipitation, exacerbation end relief of angina pectoris. Am J Cardiol 1981;48:797-803.

26. Epstein SE, Cannon RO III, Talbot TL. Hemodynamic principles in the control of coronary blood flow. Am J Cardiol 1985;56:4E-10E.

27. Ferrari M, Schnell B, Werner GS, Figulla HR. Safety of deferring angioplasty in patients with normal coronary flow velocity reserve. J Am Coll Cardiol 1999;33:82-7.

28. Bech GJ, De Bruyne B, Bonnier HJ, Bartunek J, Wijns W, Peels K, et al. Long-term follow-up after deferral of percutaneous transluminal coronary angioplasty of intermediate stenosis on the basis of coronary pressure measurement. J Am Coll Cardiol 1998;31:841-7.

29. Bech GJ, Pijls NH, De Bruyne B, Peels KH, Michels HR, Bonnier $\mathrm{HJ}$, et al. Usefulness of fractional flow reserve to predict clinical outcome after balloon angioplasty. Circulation 1999;99:883-8.

30. Ritchie JL, Trobaugh GB, Hamilton GW, Gould KL, Narahara KA, Murray JA, et al. Myocardial imaging with thallium-201 at rest and during exercise: comparison with coronary arteriography and resting and stress electrocardiography. Circulation 1977;56:66-71.

31. Bailey IK, Griffith LSC, Rouleau J, Strauss HW, Pitt W. Thallium-201 myocardial perfusion imaging at rest and during exercise: comparative sensitivity to electrocardiography in coronary artery disease. Circulation 1977;55:79-87.

32. Quinones MA, Verani MS, Haichin RM, Mahmarian JJ, Suarez J, Zoghbi WA. Exercise echocardiography versus thallium-201 single-photon emission computed tomography in evaluation of coronary artery disease: analysis of 292 patients. Circulation 1992;85:1026-31.

33. Rallidis L, Cokkinos P, Tousoulis D, Nihoyannopoulos P. Comparison of dobutamine and treadmill exercise echocardiography in inducing ischemia in patients with CAD. J Am Coll Cardiol 1997;30:1660-8.

34. Hecht HS, DeBord L, Sotomayor N, Shaw R, Dunlap R, Ryan C. Supine bicycle stress echocardiography: peak exercise imaging is superior to post exercise imaging. J Am Soc Echocardiogr 1993;6:265-71.

35. Folland ED, Vogel RA, Hartigen P, Bates ER, Beauman GJ, Fortin $\mathrm{T}$, et al, for the Veterans Affairs ACME Investigators. Relation between coronary artery stenosis assessed by visual caliper, and computer methods and exercise capacity in patients with single-vessel coronary artery disease. Circulation 1994;89:2005-14.

36. Berman JL, Wynne J, Cohn PF. Value of a multivariate approach for interpreting treadmill exercise tests in coronary artery disease. Circulation 1978;58:505-12.

37. White CW, Wright CB, Doty DB, Hiratza LF, Eastham CL, Harrison DG, et al. Does visual interpretation of the coronary arteriogram predict the physiologic importance of a coronary stenosis? N Engl J Med 1984;310:819-24. 